\title{
OBSERVATIONS ON THE SODIUM-RETAINING CORTICOID (ALDOSTERONE) IN THE URINE OF CHILDREN AND ADULTS IN RELATION TO SODIUM BALANCE AND EDEMA 1
}

\author{
BY JOHN A. LUETSCHER, JR. AND BEN B. JOHNSON with THE ASSISTANCR OF \\ ANNE DOWDY, JULIA HARVEY, WAY LEW, AND L. J. POO
}

(From the Department of Medicine, Stanford University School of Medicine, San Francisco, Cal.)

(Submitted for publication June 9, 1954; accepted July 7, 1954)

Patients with lipemic nephrosis, cardiac failure, and hepatic cirrhosis frequently accumulate an excess of extracellular fluid, distributed in a pattern characteristic of the underlying disease. These patients commonly have a marked impairment of sodium excretion, while glomerular filtration may be low, normal, or even increased (1-4). This impairment of sodium excretion suggested the presence of a stimulus to tubular reabsorption of sodium, such as a sodium-retaining hormone with an action like desoxycorticosterone. Since the chemical nature of the hormone was unknown, a biologic assay was used to measure the sodium-retaining activity of lipid extracts of human urine.

Unusually high sodium-retaining activity was present in the urine of some edematous patients with cardiac and renal disease (5). In lipemic nephrosis, this increased sodium-retaining activity was reduced when diuresis followed the use of cortisone, corticotrophin, or concentrated human serum albumin $(6,7)$. Other observers, using similar methods, have also found abnormal sodium-retaining activity in the urine of patients with nephrosis, heart failure, cirrhosis, and toxemia of pregnancy with edema (8-12).

When extracts of urine from patients with lipemic nephrosis were fractionated by chromatography, the sodium-retaining activity was found to be more polar than desoxycorticosterone (13) and to be concentrated in one fraction which closely resembles aldosterone (14-16).

The present report summarizes our results with material extracted by chloroform within 40 minutes after acidification of urine to $\mathrm{pH} 1.0$.

1 This project was supported by a research grant (A-119) from the National Institute of Arthritis and Metabolic Diseases, Public Health Service.
Although this readily hydrolyzed and extracted material does not include all of the daily output of sodium-retaining hormone, it contains a reproducible fraction of the output. The results are comparable to those obtained in other laboratories, and can be used as a basis for examination of several questions which have arisen. For example, what is the relation of the output of sodiumretaining activity to the presence of edema and to the output of sodium and water? Does the sodium-retaining material excreted in several diseases have the same chromatographic and physiologic properties? Some data related to these questions will be presented here.

\section{METHODS}

Urine was collected as 24-hour specimens in a refrigerator without preservative. Sodium was determined by flame photometer. Each day's total specimen was promptly frozen and held at $-20^{\circ} \mathrm{C}$. until extraction.

Urine was acidified to $\mathrm{pH} 1.0$ with concentrated $\mathrm{HCl}$ and was shaken with four successive portions of chloroform (not less than $100 \mathrm{cc}$. and at least 0.1 volume per volume of urine). Emulsions were broken by centrifugation. The extraction was completed within $40 \mathrm{~min}$ utes after the urine was acidified. The chloroform extracts were combined, washed with cold $0.1 \mathrm{~N}$ sodium hydroxide solution and cold distilled water, dried over anhydrous sodium sulfate, and evaporated to dryness under reduced pressure at $40^{\circ} \mathrm{C}$. The residue was taken up in redistilled ethanol.

Sodium-retaining activity was determined by bioassay (17). The results are expressed as the dose of desoxycorticosterone acetate (DCA) which would produce an equivalent effect on the excretion of sodium and potassium by adrenalectomized rats. The amount of extract given to each rat is expressed in minutes (e.g., 20 minutes $=1 / 72$ of the extract from a 24-hour specimen).

In certain instances, urine extracts increase the excretion of sodium by the adrenalectomized rats. When this result is expressed as a dose of DCA, an estimate 
less than zero (minus sign) is obtained. A similar result is seen when cortisone, hydrocortisone, or corticosterone is tested in the bioassay (17).

The present results on normal urine show sodiumretaining activity less than that found in earlier studies (18), in which the small but definite sodium-retaining effect of the injected solvent was overlooked and in which a less satisfactory method of estimating dosage was used.

\section{RESULTS}

Normal adults on unrestricted diets: Eleven healthy subjects, whose ages ranged from 22 to 40 years, showed sodium-retaining activity between +0.5 and -7.2 (average -2.8 ) $\mu \mathrm{g}$. DCA per 20 minutes of extract (Figure 1).

Normal children: Five subjects, aged 3 to 11 years, on free sodium intake, showed sodium-retaining activity between +0.5 and -0.5 (average $0.0) \mu \mathrm{g}$. DCA per 20 minutes of extract.

Restriction of sodium intake to $11 \mathrm{mEq}$. per day was followed by a systematic increase in sodiumretaining activity in six normal adults (Table I). A simple sign test suffices to demonstrate that the increases in the series reflect real changes (at the

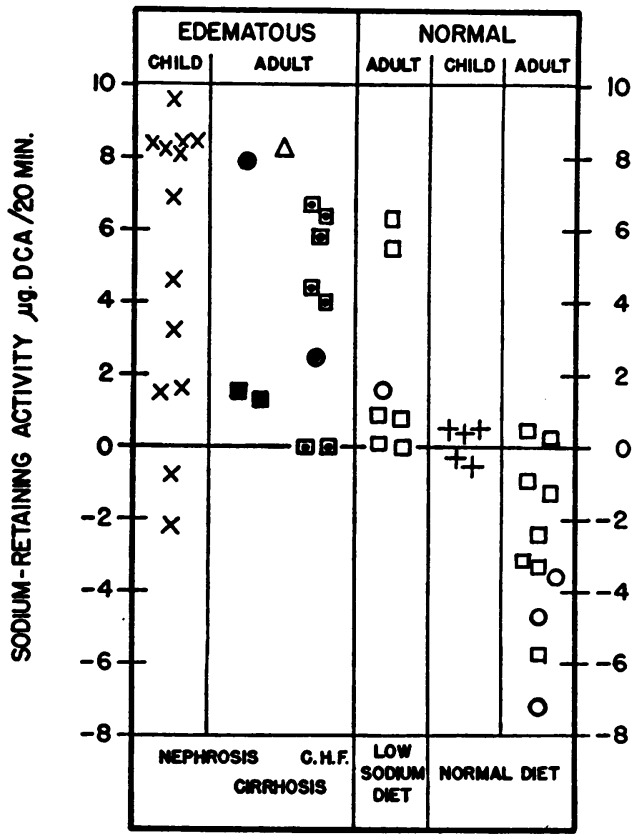

Fig. 1. Sodium-Retaining Actrvity of Urine Extracts

Symbols: Normal adults: male $\square$, female $\bigcirc$; Congestive heart failure (C.H.F.): male $\square$, female $\odot$; Adults with lipemic nephrosis: male $\square$, female $O$; Children: normal + , lipemic nephrosis $X$.
TABLE I

Effect of reduced sodium intake (11 mEq. per day) on sodium-retaining activity of urine extracts of six normal adults

\begin{tabular}{|c|c|c|c|}
\hline \multirow[b]{2}{*}{ Patient } & \multicolumn{3}{|c|}{ Sodium-retaining activity } \\
\hline & $\begin{array}{c}\text { Normal } \\
\text { diet } \\
\text { Mg. } D C A \text { CA } \\
20 \text { min. }\end{array}$ & $\begin{array}{c}\text { Low sodium } \\
\text { diet } \\
\text { Mg. } D C A / \\
20 \text { min. }\end{array}$ & Change \\
\hline $\begin{array}{l}\mathrm{He} \\
\mathrm{Wo} \\
\mathrm{Dj} \\
\mathrm{Jl} \\
\mathrm{Sp} \\
\mathrm{Sa}\end{array}$ & $\begin{array}{l}+0.5 \\
+0.3 \\
-0.9 \\
-2.4 \\
-4.7 \\
-5.7\end{array}$ & $\begin{array}{r}+6.3 \\
+5.5 \\
0.0 \\
+0.9 \\
+1.6 \\
+0.8\end{array}$ & $\begin{array}{r}+5.8 \\
+5.2 \\
+0.9 \\
+3.3 \\
+6.3 \\
+6.5\end{array}$ \\
\hline Mean & -2.15 & +2.52 & +4.67 \\
\hline
\end{tabular}

5 per cent level of significance) rather than random fluctuation. ${ }^{2}$

Adults with edema due to heart failure, lipemic nephrosis, and hepatic cirrhosis: Eight patients with congestive heart failure and edema showed sodium-retaining activity of 0 to 6.7 (average 3.7) $\mu \mathrm{g}$. DCA per 20 minutes of extract. Three edematous adults with lipemic nephrosis showed variably increased sodium-retaining activity. One patient with Laennec's cirrhosis was studied to relate the present findings with previous observations (10); sodium-retaining activity was 8.2 $\mu \mathrm{g}$. DCA per 20 minutes. The diets of these patients contained 10 to $85 \mathrm{mEq}$. sodium per day. There was no obvious relationship between sodium intake and sodium-retaining activity in this small, heterogeneous group.

Children with edema due to lipemic nephrosis: Thirteen patients showed a range of sodium-retaining activity between -2.2 and +9.6 (average 4.9) $\mu \mathrm{g}$. DCA per 20 minutes of extract. The diets contained 10 to $51 \mathrm{mEq}$. sodium per day. Sodium-retaining activity showed no significant change when a free sodium intake was given to two patients.

Relation of sodium-retaining activity to renal excretion of sodium: In Figure 2, sodium-retain-

\footnotetext{
2 More sensitive tests are possible. Each of the twelve determinations has a standard error of approximately $2.0 \mu \mathrm{g}$., since all assays involved eight or nine rats. It follows that the standard error of each difference is approximately $2.8 \mu \mathrm{g}$., and that the standard error of the average of six such differences is approximately $\frac{2.8}{\sqrt{6}} \fallingdotseq$ $1.15 \mu \mathrm{g}$. The average of the difference is $4.67 \mu \mathrm{g}$., more than three times its standard error, and thus highly significant.
} 


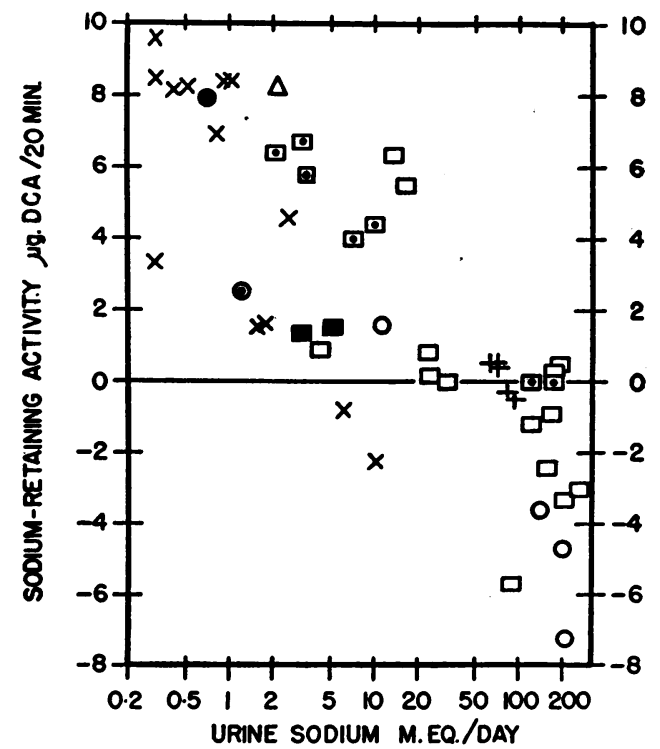

Fig. 2. Relation between Urine Sodium and SodiumRetaining Activity

Assays and symbols are the same as in Figure 1. The logarithm of urine sodium is used empirically: compare the linear response and uniform variance of $\sqrt{\mathrm{Na}}$ or $\log$ $\mathrm{K} / \mathrm{Na}$ with dose of desoxycorticosterone in adrenalectomized rats (17).

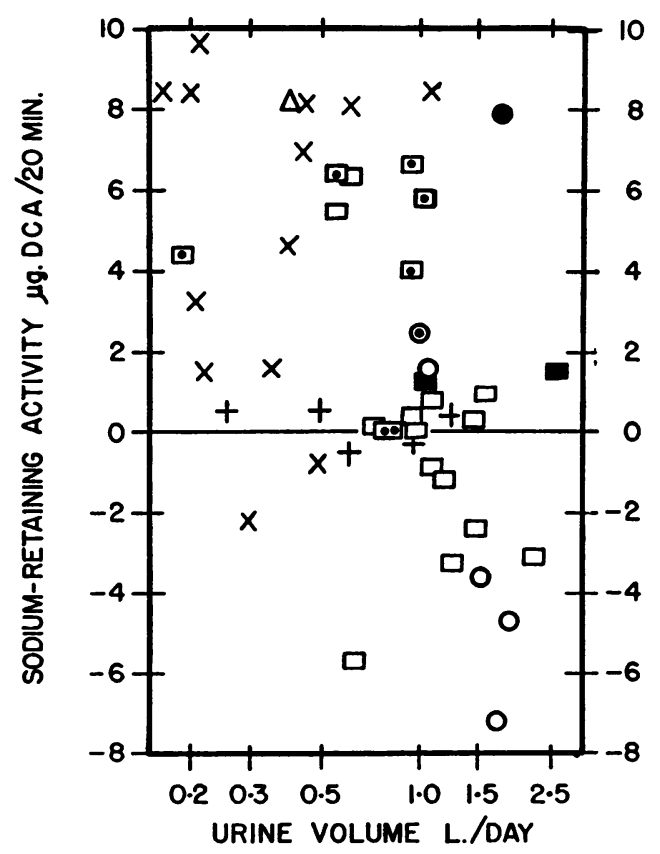

Fig. 3. Absence of Clear Relation between Urine Volume aNd Sodrum-Retaining ACtivity

Symbols in this and subsequent figures are the same as those used in Figure 1. ing activity is plotted against the sodium content of the 24-hour specimen from which the extract was made. The assays and symbols for diagnoses are the same as in Figure 1. The inverse correlation of sodium-retaining activity with sodium output is clearly evident. It is apparent that the relationship varies somewhat in different patients, as might be expected with variations in the tubular load of sodium and in the excretion and estimation of sodium-retaining activity.

Relation to urine volume: The output of sodiumretaining activity appears to be independent of urine flow (Figure 3).

Chromatographic behavior of the sodium-retaining corticoid: When urine extracts from children with nephrosis were chromatographed on paper, sodium-retaining activity was concentrated in a fraction which moved near cortisone in the toluene and propylene glycol system (14). In the benzene and aqueous methanol system, the activity was associated with a corticosteroid whose lower mobility allowed its separation from cortisone. The chromatographic behavior of this

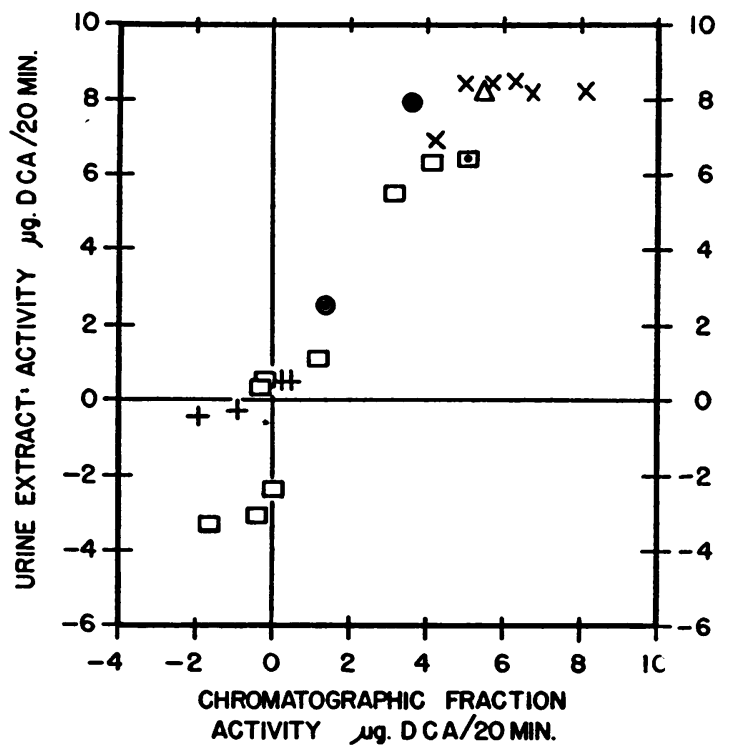

Fig. 4. Comparison of Sodium-Retaining Activity of Each Urine Extract (Ordinate) with Activity of the "E Fraction" from Toluene-Propylene Glycol. Chromatogram of that Extract (Abscissa)

The points each represent one extract; they approach, but do not reach, the $45^{\circ}$ line $(x=y)$, which would indicate complete recovery of the sodium-retaining activity of the extract in this single fraction of the chromatogram. 
sodium-retaining corticoid corresponds to that described for aldosterone (19).

In Figure 4, the sodium-retaining activity of this chromatographic fraction is compared 'with the activity of the whole extract from which the fraction was prepared. Approximately 75 per cent of the activity of the whole extract was recovered in this fraction in the 22 cases studied. Significant sodium-retaining activity has not been found in any other chromatographic fraction. ${ }^{3}$

Figure 5 shows that sodium-retaining activity may appear in this fraction in nephrosis, in congestive heart failure, and in hepatic cirrhosis. Bioassay of a comparable fraction from the urine of six adults and four children on a free sodium intake showed no sodium-retaining activity in doses equivalent to 20 to 167 minutes of extract. The restriction of sodium intake to $11 \mathrm{mEq}$. per

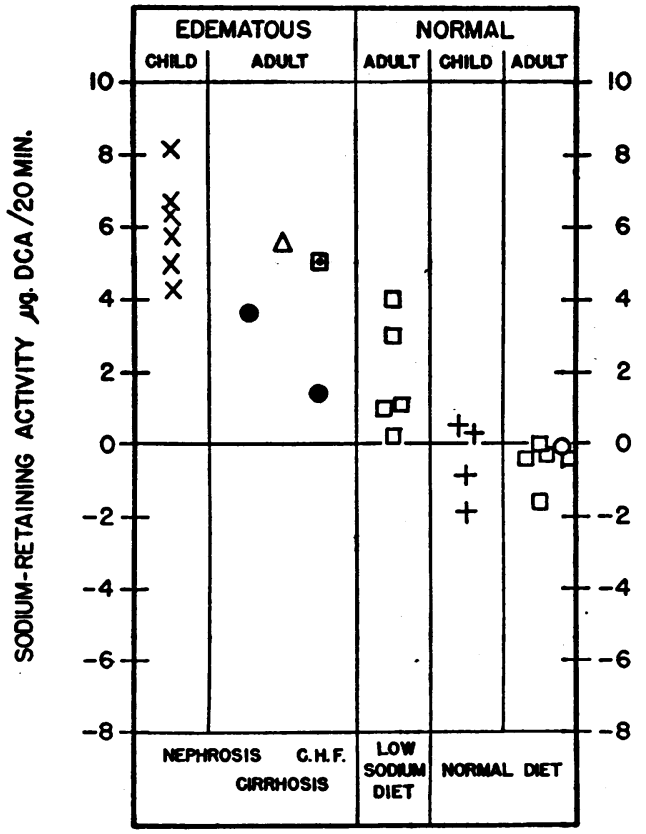

Fig. 5. Sodrum-Retaining Activity of "E Fraction" from Toluene-Propylene Glycol Chromatograms of VARIOUS URINE ExTracts

${ }^{8}$ A material which increases the output of sodium in the bioassay has been observed in the hydrocortisone fraction (14). When this material was eliminated by chromatography from the fraction in which sodium-retaining activity was sought, the latter fraction did not gain in sodium-retaining activity, as if an interfering substance had been removed; but the diuretic activity found in the urine extracts of some normal adults was reduced or eliminated (Figure 4).

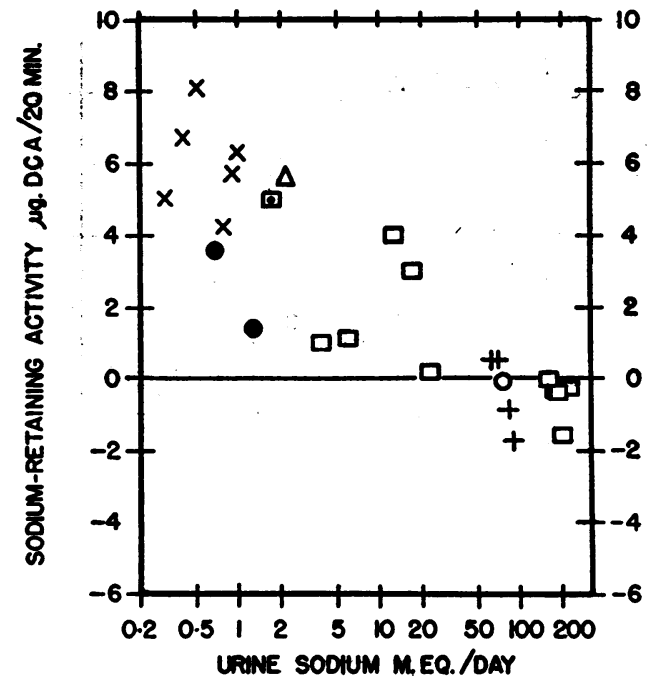

Fig. 6. Relation of Urine Sodtum and Sodium-Retaining Activity of "E Fraction" of Toluene-Propylene Glycol Chromatogram of Urine Extract

day may be followed by the appearance of appreciable sodium-retaining activity in this chromatographic fraction (Figure 5).

The relationship between sodium output and the sodium-retaining activity of this fraction separated by paper chromatography is shown in Figure 6.

\section{DISCUSSION}

If the bioassay of a sodium-retaining hormone in the urine measures an effective mechanism for conserving sodium, there should be a correlation between the output of this hormone and the patient's output of sodium. The data presented demonstrate such a relationship.

When greatly increased amounts of sodiumretaining hormone appear, accumulation of sodium and water in the body may result in edema. Edema is not of itself necessarily associated with a high output of sodium-retaining activity, however, since the output of sodium-retaining activity falls with increasing sodium output before edema is eliminated (Figures 1, 2; References 6, 7).

Increased output of sodium-retaining activity may be stimulated in normal men by reduced sodium in the diet. In this case, urine sodium is low, while a very moderate reduction of extracellular volume exists. It would appear that bioassay of sodium-retaining activity measures a 
mechanism for the conservation of sodium independent of the state of hydration.

Sodium-retaining activity can be recovered in a single chromatographic fraction of urine extract. The same fraction contains the activity observed in lipemic nephrosis, in cardiac failure, and in hepatic cirrhosis, as well as in normal men on a diet low in sodium. In children with lipemic nephrosis, this active fraction has been found to contain a corticosteroid resembling aldosterone in a number of physical and chemical properties and in its ability to increase sodium reabsorption by the renal tubules $(14,15)$.

The failure to demonstrate sodium-retaining activity in extracts of normal human urine indicates only that readily hydrolyzed complexes are present in quantities too small to assay. More prolonged hydrolysis at $\mathrm{pH} 1.0$ releases assayable quantities of sodium-retaining hormone from normal urine (20). Since this normal output disappears in patients subjected to adrenalectomy (20), it seems highly probable that the sodium-retaining hormone arises in the adrenal cortex.

The output of sodium-retaining hormone does not appear to be under the control of pituitary corticotrophin (21). The stimulus to increased output would appear best defined by an "inadequacy" of the circulation, including depletion of plasma or extracellular volume, as suggested by Peters (22). Since a number of the patients studied were not able to accept a full normal diet, it is possible that sodium intake was subnormal even when there was no deliberate restriction. Present experience indicates that the increased sodium-retaining activity in disease is not dependent upon low sodium intake alone, although reduced sodium intake may further increase the high levels observed.

\section{SUMMARY}

Forty-eight specimens of urine from normal adults and children and from hospitalized patients have been extracted with chloroform within 40 minutes after acidification to $\mathrm{pH} 1.0$. The sodium-retaining activity of the extracted material has been measured by bioassay. Significant sodium-retaining activity was observed in extracts prepared from the urine of a number of edematous patients with lipemic nephrosis, cardiac failure, and hepatic cirrhosis.
Urine extracts from normal men and women often had an opposite effect, tending to increase the excretion of sodium in the adrenalectomized rats, resembling the effect of hydrocortisone in the bioassay used.

Increased sodium-retaining activity was found in the urine of some normal men and women when sodium intake was rediced to $11 \mathrm{mEq}$. per day.

The level of sodium-retaining activity appeared to be related to the daily output of sodium by the patient, rather than to a specific disease, to the state of hydration, or to urine flow.

The sodium-retaining activity of extracts of urine from several patients with lipemic nephrosis, cardiac failure, or hepatic cirrhosis was found in the same chromatographic fraction of each extract tested. Some normal men on low sodium diets showed increased activity in the same fraction of the chromatograms. This fraction has been observed to contain a corticosteroid which is presumed to be aldosterone on the basis of its chromatographic and biologic properties.

\section{ACKNOWLEDGMENTS}

The authors wish to thank Dr. B. J. Axelrad for performing several of the bioassays reported here, and Dr. L. E. Moses for advice on statistical methods. The assistance of the medical, nursing, and dietetic staffs of Stanford University Hospitals is gratefully acknowledged.

\section{REFERENCES}

1. Merrill, A. J., Mechanisms of salt and water retention in heart failure. Am. J. Med., 1949, 6, 357.

2. Sinclair-Smith, B., Kattus, A. A., Genest, J., and Newman, E. V., The renal mechanism of electrolyte excretion and the metabolic balances of electrolytes and nitrogen in congestive cardiac failure; the effects of exercise, rest and aminophyllin. Bull. Johns Hopkins Hosp., 1949 84, 369.

3. Luetscher, J. A., Jr., Hall, A. D., and Kremer, V. L., Treatment of nephrosis with concentrated human serum albumin. II. Effects on renal function and on excretion of water and some electrolytes. J. Clin. Invest., 1950, 29, 896.

4. Goodyer, A. V. N., Relman, A. S., Lawrason, F. D., and Epstein, F. H., Salt retention in cirrhosis of the liver. J. Clin. Invest., 1950, 29, 973.

5. Deming, Q. B., and Luetscher, J. A., Jr., Bioassay of desoxycorticosterone-like material in urine. Proc. Soc. Exper. Biol. \& Med., 1950, 73, 171.

6. Luetscher, J. A., Jr., and Deming, Q. B., Treatment of nephrosis with cortisone. J. Clin. Invest., 1950, 29, 1576. 
7. Luetscher, J. A., Jr., Deming, Q. B., and Johnson, B. B., Treatment of nephrosis with pituitary adrenocorticotrophin. J. Clin. Invest., 1951, 30, 1530.

8. McCall, M. F., and Singer, B., Studies in nephrosis. Chemical corticoids, salt-retaining factor, and effect of ACTH. J. Clin. Endocrinol. \& Metab., 1953, 13, 1157.

9. Singer, B., and Wener, J., Excretion of sodiumretaining substances in patients with congestive heart failure. Am. Heart J., 1953, 45, 795.

10. Chart, J. J., and Shipley, E. S., The mechanism of sodium retention in cirrhosis of the liver. J. Clin. Invest., 1953, 32, 560.

11. Chart, J. J., Shipley, E. G., and Gordon, E. S., Evidence for a sodium-retaining factor in toxemia of pregnancy. Proc. Soc. Exper. Biol. \& Med., 1951, 78, 244.

12. Venning, E. H., Singer, B., and Simpson, G. A., Adrenocortical function in toxemia of pregnancy. Am. J. Obst. \& Gynec., 1954, 67, 542.

13. Luetscher, J. A., Jr., Deming, Q. B., and Johnson, B. B., The sodium-retaining activity of the corticoid fraction of urine of oedematous patients in Anterior Pituitary Secretion and Hormonal Influences on Water Metabolism. Ciba Foundation Colloquia on Endocrinology, Vol. IV, G. E. W. Wolstenholme, Ed., London, J. and A. Churchill, 1952, p. 530.

14. Luetscher, J. A., Jr., and Johnson, B. B., Chromatographic separation of the sodium-retaining corticoid from the urine of children with nephrosis, compared with observations on normal children. J. Clin. Invest., 1954, 33, 276.

15. Sala, G., and Luetscher, J. A., Jr., The effect of sodium-retaining corticoid, electrocortin, desoxy- corticosterone, and cortisone on renal function and excretion of sodium and water in adrenalectomized rats. Endocrinology, in press.

16. Simpson, S. A., Tait, J. F., Wettstein, A., Neher, R., v. Euw, J., Schindler, O., and Reichstein, T., Konstitution des aldosterons, des neuen mineralocorticoids. Experientia, 1954, 10, 132.

17. Johnson, B. B., Bioassay of adrenal cortical steroids on the basis of electrolyte excretion by rats: effects of 11-desoxy and 11-oxy-steroids. Endocrinology, 1954, 54, 196.

18. Luetscher, J. A., Jr., and Deming, Q. B., Bioassay of sodium-retaining corticoids and some changes in excretion of these substances in disease in Renal Function, Transactions of the Second Conference, Oct. 19-20, 1950, ed. by S. E. Bradley, New York, Josiah Macy, Jr. Foundation, 1951, p. 155.

19. Simpson, S. A., and Tait, J. F., Physico-chemical methods of detection of a previously unidentified adrenal hormone in The Determination of Adrenocortical Steroids and Their Metabolites, Society for Endocrinology, Memoir No. 2, ed. by P. Eckstein and S. Zuckerman, London, Dennis Dobson, 1953, p. 9.

20. Luetscher, J. A., Jr., and Axelrad, B. J., Sodiumretaining corticoid in the urine of normal children and adults and of patients with hypoadrenalism or hypopituitarism. J. Clin. Endocrinol. \& Metab., in press.

21. Axelrad, B. J., Johnson, B. B., and Luetscher, J. A., Jr., Factors regulating the output of sodium-retaining corticoid of human urine. J. Clin. Endocrinol. \& Metab., in press.

22. Peters, J. P., The role of sodium in the production of edema. New England J. Med., 1948, 239, 353. 